\title{
Outcomes of patients with human immunodeficiency virus infection undergoing cardiovascular surgery in the United States
}

\author{
Michael P. Robich, MD, ${ }^{\mathrm{a}}$ Nicholas Schiltz, PhD, ${ }^{\mathrm{b}}$ Douglas R. Johnston, MD, ${ }^{\mathrm{a}}$ Stephanie Mick, MD, ${ }^{\mathrm{a}}$ \\ Wayne Tse, BS, ${ }^{a}$ Colleen Koch, MD, MS, MBA, ${ }^{c}$ and Edward G. Soltesz, MD, MPH ${ }^{\mathrm{a}}$
}

\begin{abstract}
Introduction: Advances in highly active antiretroviral therapy have dramatically improved the lifespan of patients infected with human immunodeficiency virus (HIV). We sought to examine the impact of HIV status on outcomes in patients undergoing cardiovascular surgery.
\end{abstract}

\begin{abstract}
Methods: We identified 5,621,817 patients who underwent coronary artery bypass graft (CABG), valve, aortic, or other cardiovascular surgery between 1998 and 2009 from the Nationwide Inpatient Sample. Of these, $9771(0.17 \%)$ patients were seropositive for HIV. Using multivariable logistic regression modeling and 1:1 propensity-score matching, we determined the influence of HIV infection on outcomes.

Results: The percentage of HIV+ patients undergoing cardiovascular surgery increased significantly from $0.09 \%$ to $0.23 \%$. HIV + patients were more often male, black, younger than 55 years of age, and on Medicaid, and they were more likely to undergo valve and other cardiovascular surgeries, but less likely to have CABG. Among propensity-matched pairs, patients with HIV were at no increased risk for in-patient mortality. HIV + patients were more likely to receive a blood transfusion and have any postoperative complication. Patients with HIV were less likely to have a postoperative stroke. Rates of pneumonia, renal complications, and wound infection were similar between the groups. The median length of stay and mean total cost were not different between the groups. Factors that predicted in-hospital death in HIV+ patients included metastatic cancer, coagulopathy, renal failure, and aortic, other, or combined surgical procedure.
\end{abstract}

Conclusions: Cardiovascular surgery can be performed safely on patients with HIV with no increased hospital mortality and only minimal increased need for blood transfusion. (J Thorac Cardiovasc Surg 2014;148:3066-75)

Advances in highly active antiretroviral therapy (HAART) have dramatically improved the prognosis of patients positive for human immunodeficiency virus (HIV). ${ }^{1}$ HAART has extended the lives of HIV + patients by decreasing viral load and increasing CD4 T cell counts. ${ }^{2}$ The combination of immune reconstitution, improved antibiotic prophylaxis, and increased access to care has drastically ameliorated the incidence of life-threatening opportunistic infections in HIV + patients. ${ }^{3}$ Despite an actual increase in the prevalence of HIV infection, the overall morbidity and mortality of HIV infection have substantially decreased, allowing many

From the Department of Thoracic and Cardiovascular Surgery, ${ }^{\mathrm{a}}$ Heart and Vascular Institute, Cleveland Clinic, Cleveland, Ohio; Department of Epidemiology and

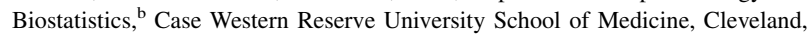
Ohio; and Department of Cardiothoracic Anesthesia, ${ }^{\mathrm{c}}$ Cleveland Clinic, Cleveland, Ohio.

Disclosures: Douglas R. Johnston reports consulting fees from St. Jude Medical, Edwards Lifesciences, and JAC Medical, and equity ownership in JAC Medical Edward G. Soltesz reports consulting fees for Estech and lecture fees from St. Jude Medical and Edwards Lifesciences. All other authors have nothing to disclose with regard to commercial support.

Read at the 94th Annual Meeting of The American Association for Thoracic Surgery, Toronto, Ontario, Canada, April 26-30, 2014.

Received for publication April 28, 2014; revisions received July 12, 2014; accepted for publication July 20, 2014; available ahead of print Aug 28, 2014.

Address for reprints: Edward G. Soltesz, MD, MPH, Department of Thoracic and

Cardiovascular Surgery, Cleveland Clinic, 9500 Euclid Ave (Desk J4-1),

Cleveland, OH 44195 (E-mail: soltese@ccf.org).

$0022-5223 / \$ 36.00$

Copyright (C) 2014 by The American Association for Thoracic Surgery

http://dx.doi.org/10.1016/j.jtcvs.2014.07.074
HIV + patients to live much longer with what is now considered a chronic disease. A growing population of patients with HIV is now developing cardiovascular disease. Traditional cardiovascular risk factors such as hypertension, hyperlipidemia, and metabolic syndrome are known to be exacerbated by antiretroviral drugs. ${ }^{4-6} \mathrm{HIV}+$ patients on HAART have an increased risk of developing coronary artery disease (CAD) and myocardial infarction (MI). ${ }^{7-9}$ Accordingly, the number of HIV+ patients requiring some form of cardiovascular surgery is increasing.

Outcomes of cardiovascular surgery in HIV+ patients have been described in smaller patient series. Cardiovascular surgery using cardiopulmonary bypass does not seem to accelerate immunodeficiency or produce adverse effects in patients with HIV. ${ }^{10}$ Although many studies have shown that cardiovascular surgery in HIV+ patients can be performed safely with acceptable mortality, there seems to be higher rates of complications in this patient population. ${ }^{11}$ The outcomes from a population-based perspective, however, are still unknown. The aim of this study was to examine the impact of HIV infection on mortality, complications, length of stay, and cost in patients undergoing cardiovascular surgery.

\section{PATIENTS AND METHODS \\ Data}

The Nationwide Inpatient Sample (NIS) Healthcare Cost Utilization Project (HCUP) database was queried from 1998 to 2009 for patients 


$$
\begin{aligned}
& \text { Abbreviations and Acronyms } \\
& \begin{array}{ll}
\text { CABG } & =\text { coronary artery bypass graft } \\
\text { CAD } & =\text { coronary artery disease } \\
\text { CCS } & =\text { Clinical Classifications Software } \\
\text { CI } & =\text { confidence interval } \\
\text { HAART } & =\text { highly active antiretroviral therapy } \\
\text { HCUP } & =\text { Healthcare Cost Utilization Project } \\
\text { HIV } & =\text { human immunodeficiency virus } \\
\text { MI } & =\text { myocardial infarction } \\
\text { NIS } & =\text { Nationwide Inpatient Sample } \\
\text { OR } & =\text { odds ratio }
\end{array}
\end{aligned}
$$

undergoing cardiovascular surgery using the 2003 International Classification of Diseases, Ninth Revision, Clinical Modification (ICD-9-CM) diagnosis and procedure codes. The NIS is the largest all-payer inpatient discharge database. The patients represent a $20 \%$ stratified sample of all discharges occurring in a given year from approximately 1000 hospitals in 24 to 45 states (depending on the year of the study). The database contains information on about 8 million discharges per year. Individual entries in the database contain information on demographics, comorbidity, hospital charges, length of stay, procedures, outcomes, and discharge. Discharge weights are provided, which allow extraction of nation-level estimates from the unweighted database information. Weighted estimates are reported throughout. Patients who underwent cardiovascular surgery were identified using the preexisting Clinical Classifications Software (CCS) procedure codes 43 (heart valve surgery), 44 (coronary bypass surgery), 49 (other operating room heart procedure), and 52 (aortic surgery). ${ }^{12}$ Furthermore, we excluded certain procedures within CCS 49 that we felt were not necessarily cardiovascular surgeries if they were the primary procedure: ICD-9-CM 37.34 (excision of other heart lesion via catheter), 37.61 (insertion of intra-aortic balloon pump), 37.68 (insertion of percutaneous heart assist device), 37.90 (insertion of left atrial appendage device), 37.91 (open chest cardiac massage), and 37.99 (removal of pacemaker device). Patients with a history of HIV infection were identified using the predefined CCS diagnosis code 5. The patients who underwent cardiovascular surgery without a diagnosis of HIV infection were used as a comparison group. Patients less than 18 and more than 100 years old were excluded. The database provides de-identified, publically available data and use does not require institutional review board approval.

\section{Population}

Data on 5,631,589 patients who underwent cardiovascular surgery were available in the NIS for analysis. There were $9771(0.17 \%)$ patients who had a diagnosis of HIV infection.

\section{Outcomes}

The outcomes analyzed for each hospitalization were in-hospital mortality, length of stay, discharge disposition, hospital charges and cost, and complications. The complications were identified through secondary ICD-9-CM codes and included stroke, blood transfusion, wound infection, acute renal failure, pneumonia, and the composite outcome of any complication. Hospital resource consumption was evaluated by hospitalization charges and hospitalization cost. The categories of disposition were routine discharge, transfer to another inpatient facility, transfer to another type of facility (including acute care and skilled nursing facilities), and home health care. Total charges represent the amount hospitals billed for services and do not include professional fees. Total costs were derived from total charges using a cost-to-charge ratio created by HCUP that is based on accounting reports from the Centers for Medicare and Medicaid Services. Hospital costs tend to better estimate resource use because hospital charges often reflect payor policies and other factors unrelated to resource use. Cost was calculated by multiplying total charges with the hospital-specific cost-to-charge ratio. Costs were adjusted for inflation and converted to 2009 US dollars using the appropriate Consumer Price Index.

\section{Covariables}

We considered demographics, comorbidities, insurance status, hospital characteristics, and the region where procedures were performed. Patientlevel variables included age, sex, race, and insurance status. Race/ethnicity was categorized as white, black, Hispanic, and other/missing. Certain states do not document race on discharge records, and thus race is missing for approximately $25 \%$ of the study population. Insurance status was categorized as Medicare, Medicaid, private insurance, uninsured, and other based on the primary payer listed on the discharge record. Comorbidities for risk adjustment were derived from secondary ICD-9-CM diagnosis codes using a modification of the approach developed by Elixhauser and colleagues. ${ }^{1.3}$ We excluded several of the 30 comorbidities because they were either the focus of the study (HIV) or were too few in number (eg, pulmonary circulation disorders, chronic peptic ulcer disease). A hospital was considered to be a teaching hospital if it had a residency program approved by the American Medical Association, was a member of the Council of Teaching Hospitals, or had a ratio of full-time equivalent interns and residents to beds of 0.25 or higher. Hospital region was classified by the US Census Bureau as northeast, midwest, south, or west. Hospital bed size was classified as small, medium, or large, based on an algorithm developed by HCUP. Surgical procedure was categorized as isolated coronary artery bypass graft (CABG), isolated valve repair or replacement, isolated aortic surgery, other operative heart surgery, or a combination of 2 or more of these.

\section{Statistical Analysis}

The mean, median, and standard deviation were calculated for all continuous outcomes, and frequency counts and percentages for categorical outcomes. Appropriate statistical tests were used for categorical ( $\chi^{2}$ test) and continuous (Student $t$ test) outcomes to compare unadjusted differences by previous transplant status. All data included in the present study are weighted data from the NIS database.

\section{Matching}

Propensity scores, or the conditional probability of having a history of HIV infection, were estimated for each patient using a multivariable logistic regression model in which the presence of HIV was the dependent variable and patient demographics, payer status, comorbidities, hospital characteristics, and procedure type were the independent variables. The purpose of the propensity score was to balance the covariables for patients with and without HIV infection in order to assess outcomes without influence from known factors. To match those with and without HIV infection, we used a 1:1 greedy matching algorithm with a caliper of 0.2 times the standard deviation of the linear propensity score. The balance of covariables before and after matching was assessed by calculating the standardized differences between those with and without HIV. ${ }^{14}$ We also performed $\chi^{2}$ tests for all covariables before matching, and the McNemar test in the matched sample. Propensity matching resulted in 1633 pairs of patients with and without a history of HIV who were well-matched with respect to demographics, comorbidities, surgical procedures, and institutional characteristics (ie, region, teaching status, and so forth) (Figure 1). After matching, we compared outcomes between the HIV+ group and the HIV - controls using difference in means with paired $t$ tests for costs and length of stay, and conditional logistic regression for mortality and complication outcomes.

All analyses were performed using the SAS System for Unix, version 9.2 (SAS Institute, Inc, Cary, NC). 


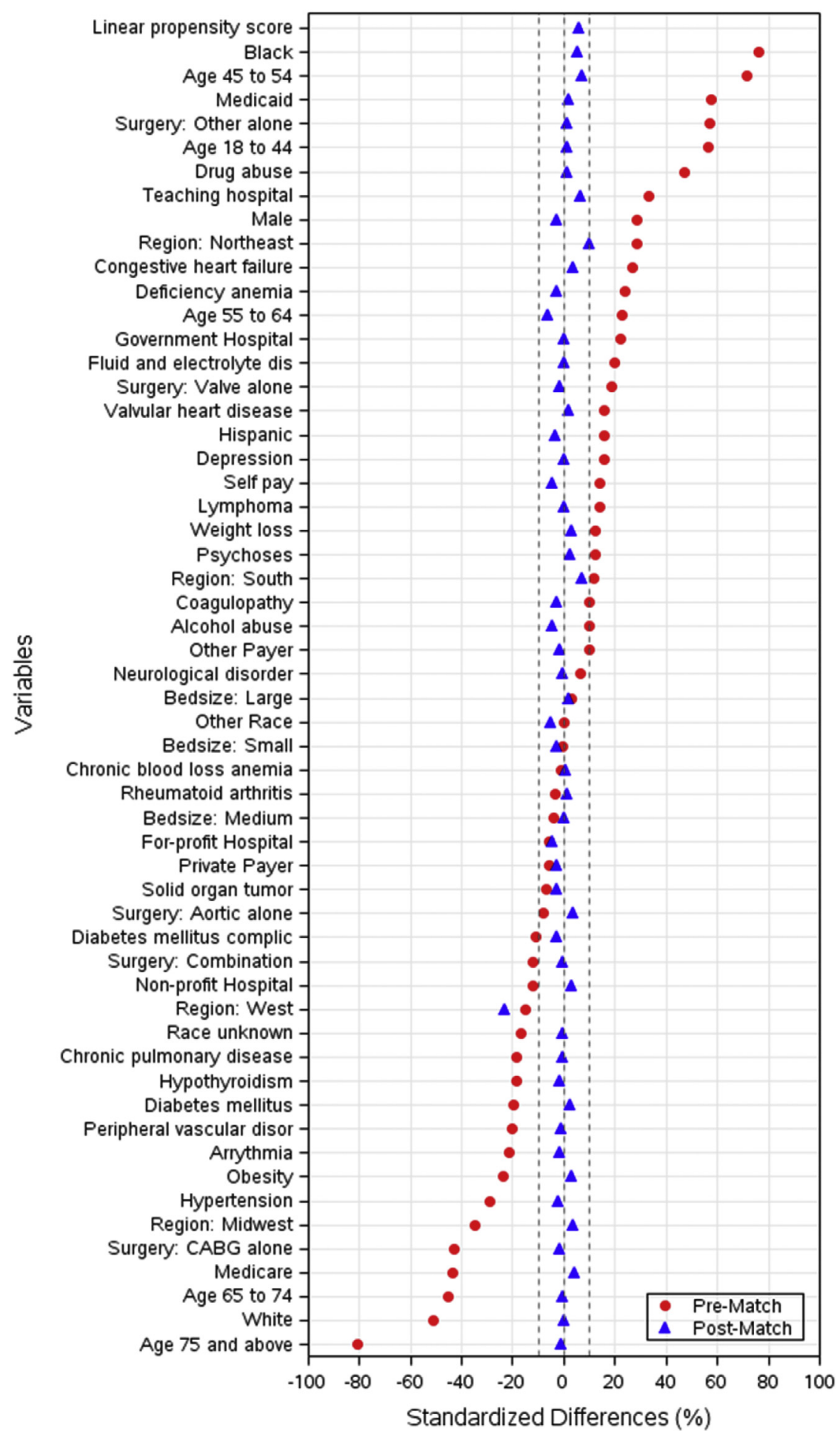

FIGURE 1. Covariance balance plot for patients with and without HIV before and after propensity matching. CABG, Coronary artery bypass graft.

\section{RESULTS}

\section{Patient Characteristics}

Over the course of the study, the percentage of patients with HIV undergoing cardiac surgery increased significantly from $0.09 \%$ to $0.23 \%(P<.001)$. The association between demographic variables and HIV status is shown in Table 1. Patients with HIV were more often male $(80 \%$ vs $68 \%$ ), black ( $33 \%$ vs $5 \%$ ), and Hispanic ( $9 \%$ vs $4 \%$ ), and less likely to be white (4\% vs $61 \%$ ) (all $P<.001$ ). $\mathrm{HIV}+$ patients were also younger with a mean age of 
TABLE 1. Distribution of operative and demographic characteristics according to HIV status

\begin{tabular}{|c|c|c|c|}
\hline Characteristic & $\begin{array}{c}\text { HIV } \\
(\mathbf{n}=9771), \\
\text { no. }(\%)\end{array}$ & $\begin{array}{c}\text { No HIV } \\
(\mathrm{n}=\mathbf{5 , 6 2 1 , 8 1 7 )}, \\
\text { no. }(\%)\end{array}$ & $P$ \\
\hline Age group & & & $<.001$ \\
\hline $0-44$ y & $3278(34)$ & $309,509(6)$ & \\
\hline $45-54$ y & 3774 (39) & $718,173(13)$ & \\
\hline $55-64$ y & $1989(20)$ & $1,337,328(23)$ & \\
\hline $65-74$ y & $628(6)$ & $1,783,167(32)$ & \\
\hline$\geq 75 \mathrm{y}$ & $102(1)$ & $1,473,640(26)$ & \\
\hline Mean age, $\mathrm{y} \pm \mathrm{SD}$ & $48.9 \pm 0.28$ & $65.6 \pm 0.05$ & $<.001$ \\
\hline Sex & & & $<.001$ \\
\hline Male & $7770(80)$ & $3,799,705(68)$ & \\
\hline Female & $2001(20)$ & $1,822,112(32)$ & \\
\hline Race/ethnicity & & & $<.001$ \\
\hline White & $399(4)$ & $3,449,276(61)$ & \\
\hline Black & $3175(33)$ & $259,786(5)$ & \\
\hline Hispanic & $840(9)$ & 250,248 (4) & \\
\hline Other/missing & $3606(37)$ & $1,662,507(30)$ & \\
\hline Primary payer & & & $<.001$ \\
\hline Medicare & $3306(34)$ & $3,087,491(55)$ & \\
\hline Medicaid & $2361(24)$ & $258,039(5)$ & \\
\hline Private & $3101(32)$ & $1,963,737(35)$ & \\
\hline Uninsured & $617(6)$ & $163,692(3)$ & \\
\hline Other & $368(4)$ & $138,072(3)$ & \\
\hline \multicolumn{4}{|c|}{ Hospital characteristics } \\
\hline Region & & & $<.001$ \\
\hline Northeast & $3164(32)$ & $1,112,977(20)$ & \\
\hline Midwest & $1079(11)$ & $1,372,462(24)$ & \\
\hline South & $4420(45)$ & $2,218,328(40)$ & \\
\hline West & $1108(12)$ & $918,051(16)$ & \\
\hline Teaching status & & & $<.001$ \\
\hline Teaching & $7623(78)$ & $3,547,014(63)$ & $<.001$ \\
\hline Nonteaching & $2101(22)$ & $2,064,089(37)$ & \\
\hline \multicolumn{4}{|l|}{ Hospital bed size } \\
\hline Small & $522(5)$ & $310,071(6)$ & \\
\hline Medium & $1724(18)$ & $1,071,572(19)$ & \\
\hline Large & $7479(77)$ & $4,229,460(75)$ & \\
\hline
\end{tabular}

$S D$, Standard deviation; $H I V$, human immunodeficiency virus.

$49 \pm 0.3$ years versus $66 \pm 0.1$ years for HIV - patients. Among the older age groups, HIV+ patients were less prevalent (age $65-74$ years, 6\% HIV + vs 32\% HIV-; age $>75$ years, $1 \%$ vs $26 \%$; both $P<.001$ ). Patients with HIV undergoing cardiovascular surgery were more likely on Medicaid ( $24 \%$ vs $5 \%$ ) or uninsured $(6 \%$ vs $3 \%)$, and were less likely on Medicare (34\% vs $55 \%)$ (all $P<.001$ ).

Geographically, patients with HIV were more likely than patients without HIV to be operated on in the northeast (32\% vs $20 \%$ ) and the south ( $45 \%$ vs $40 \%$ ) and less likely in the midwest $(11 \%$ vs $24 \%$ ) (all $P<.001)$. HIV + patients were more often treated in an academic hospital $(78 \%$ vs $63 \% ; P<.001)$. The comorbid conditions among $\mathrm{HIV}+$ and HIV- patients are listed in Table 2. Overall,
TABLE 2. Distribution of comorbid conditions according to HIV status

\begin{tabular}{|c|c|c|c|}
\hline Characteristic & $\begin{array}{c}\text { HIV } \\
(\mathrm{n}=\mathbf{9 7 7 1}), \\
\text { no. }(\%)\end{array}$ & $\begin{array}{c}\text { No HIV } \\
(\mathrm{n}=\mathbf{5 , 6 2 1 , 8 1 7 )}, \\
\text { no. }(\%)\end{array}$ & $\boldsymbol{P}$ \\
\hline Hypertension & $4133(42)$ & $3,219,625(57)$ & $<.001$ \\
\hline Heart failure & $640(6.5)$ & $77,505(1.4)$ & $<.001$ \\
\hline Peripheral arterial disease & $603(6.2)$ & $696,943(12)$ & $<.001$ \\
\hline Drug abuse & $1161(12)$ & $37,407(0.7)$ & $<.001$ \\
\hline Alcohol abuse & $350(3.6)$ & $108,092(1.9)$ & $<.001$ \\
\hline Endocarditis & $610(6.2)$ & $49,339(0.88)$ & $<.001$ \\
\hline Arrhythmia & $1708(18)$ & $1,463,292(26)$ & $<.001$ \\
\hline Weight loss & $370(3.8)$ & 96,991 (1.7) & $<.001$ \\
\hline Obesity & $298(3)$ & $488,338(8.7)$ & $<.001$ \\
\hline Diabetes & $1489(15)$ & $1,296,960(23)$ & $<.001$ \\
\hline Diabetes + complications & $198(2)$ & $215,448(3.8)$ & $<.001$ \\
\hline Rheumatoid disease & $103(1.1)$ & $87,371(1.6)$ & .068 \\
\hline Renal failure & $1522(16)$ & $364,625(6.5)$ & $<.001$ \\
\hline Cancer & $291(3)$ & $234,425(4.2)$ & .010 \\
\hline Lymphoma & $219(2.2)$ & $24,059(0.4)$ & $<.001$ \\
\hline Anemia & $1957(20)$ & $632,304(11)$ & $<.001$ \\
\hline Coagulopathy & $1129(12)$ & $473,288(8.4)$ & $<.001$ \\
\hline Chronic lung disease & $718(28)$ & $1,153,123(21)$ & $<.001$ \\
\hline Hypothyroidism & $259(2.7)$ & $361,689(6.4)$ & $<.001$ \\
\hline
\end{tabular}

the HIV+ group was sicker with a higher mean Elixhauser comorbidity index (5.0 vs $3.8 ; P<.001)$. In addition, there was a significantly higher proportion of endocarditis among $\mathrm{HIV}+$ patients $(6.24 \%$ vs $0.88 \% ; P<.001)$.

The distribution of surgeries between HIV+ and HIVpatients is shown in Figure 2. Patients with HIV were more likely to undergo isolated valve operations ( $16 \%$ vs $10 \%$ ), but less likely to have coronary bypass surgery (38\% vs $59 \%$ ) (both $P<.001$ ). Patients with HIV also had many more cardiovascular surgeries that were classified as other operating room heart procedure $(28 \%$ vs $7 \%$; $P<.001)$; most of these procedures $(84 \%)$ were open pericardial drainage operations.

\section{Outcomes}

Unadjusted outcomes between HIV + and HIV - patients are presented in Table 3. Inpatient mortality was higher among patients with $\operatorname{HIV}(7.2 \%$ vs $4.3 \% ; P<.001)$. Among patients undergoing cardiac surgeries exclusive of pericardial drainage procedures, mortality was similar between HIV+ and HIV- patients $(3.6 \%$ vs $4.0 \%$; $P=.432)$, whereas among patients undergoing only pericardial drainage procedures, HIV + patients had significantly higher mortality $(17.6 \%$ vs $10.7 \%$; $P<.001)$. Patients with HIV also had higher rates of any complication $(40 \%$ vs $30 \%)$, blood transfusion $(24 \%$ vs $19 \%)$, renal complication $(10 \%$ vs $8 \%$ ), and pneumonia ( $11 \%$ vs $5 \%)$, but lower rates of stroke $(1.2 \%$ vs $2.3 \%)$ (all $P<.001$ ). There was no difference in rates of wound 


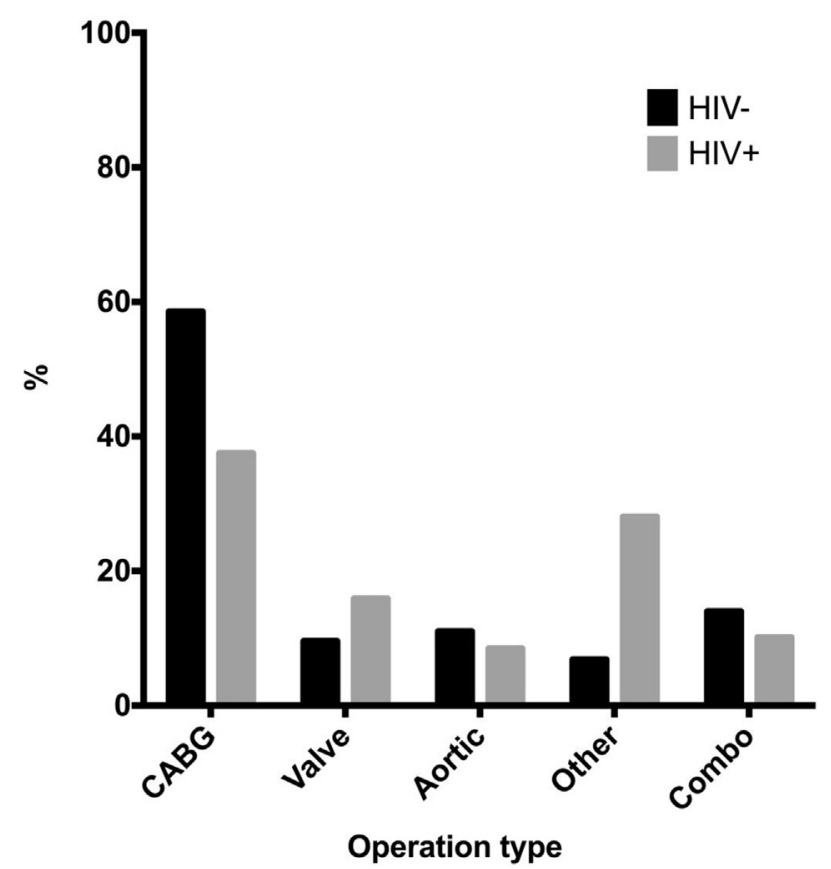

FIGURE 2. Distribution of surgeries between HIV + and HIV - patients $(P<.001) . C A B G$, Coronary artery bypass graft; Combo, combined surgery; $H I V$, human immunodeficiency virus.

infection. The median length of stay was longer for HIV+ patients ( 9 days [15th percentile, 5 days; 85 th percentile, 21 days] vs 7 days [15th percentile, 4 days; 85 th percentile, 14 days]; $P<.001$ ), and mean total cost was higher among $\mathrm{HIV}+$ patients (US $\$ 42,985 \pm 1074$ vs US $\$ 38,116 \pm 295$; $P<.001)$. There was no difference in disposition: home versus home with home health care versus transfer to another inpatient facility or other facility.

Outcomes between HIV + and HIV- patients after propensity-score matching are displayed in Table 4. The

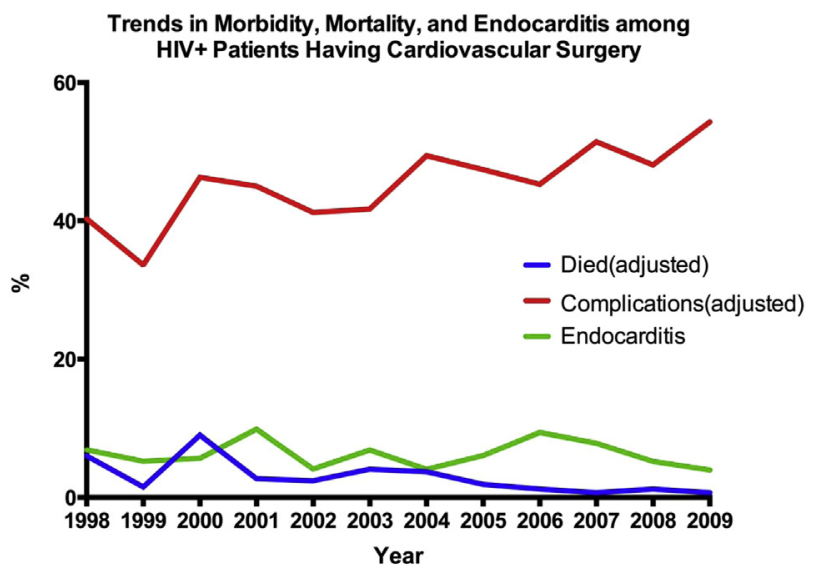

FIGURE 3. Trends in incidence of death $(P=.021)$, complications $(P=.035)$, and endocarditis $(P=.672)$ among patients with HIV undergoing cardiovascular surgery during the study period. HIV, Human immunodeficiency virus.
TABLE 3. Unadjusted outcomes for patients with and without HIV

\begin{tabular}{|c|c|c|c|}
\hline Variable & $\begin{array}{c}\text { HIV } \\
(\mathrm{n}=9771)\end{array}$ & $\begin{array}{c}\text { No HIV } \\
(\mathrm{n}=\mathbf{5 , 6 2 1 , 8 1 7 )}\end{array}$ & $\boldsymbol{P}$ \\
\hline $\begin{array}{l}\text { Median length of stay, } \\
\text { d [15th, 85th percentiles] }\end{array}$ & $9[5,21]$ & $7[4,14]$ & $<.0001$ \\
\hline $\begin{array}{l}\text { Total charges, mean } \\
\text { US } \$ \pm \text { SD }\end{array}$ & $110,915 \pm 3105$ & $91,985 \pm 1190$ & $<.0001$ \\
\hline $\begin{array}{l}\text { Total cost, mean US } \$ \text { SD } \\
\text { Hospital mortality, } \mathrm{n}(\%)\end{array}$ & $42,985 \pm 1074$ & $38,116 \pm 295$ & $<.0001$ \\
\hline Overall & $704(7.2)$ & $242,404(4.3)$ & $<.0001$ \\
\hline Pericardial surgeries & (17.6) & $(10.7)$ & $<.001$ \\
\hline Nonpericardial surgeries & $(3.6)$ & $(4.0)$ & .432 \\
\hline \multicolumn{4}{|l|}{ Complications, n (\%) } \\
\hline Any complication & 3764 (38.5) & $1,662,975(29.6)$ & $<.001$ \\
\hline Stroke & $113(1.2)$ & $128,967(2.3)$ & $<.001$ \\
\hline Blood transfusion & $2378(24.3)$ & $1,056,521(18.8)$ & $<.001$ \\
\hline Renal complication & $1012(10.4)$ & $455,953(8.1)$ & $<.001$ \\
\hline Wound infection & $125(1.3)$ & $68,094(1.2)$ & .794 \\
\hline Pneumonia & $1091(11.2)$ & $296,141(5.3)$ & $<.0001$ \\
\hline $\begin{array}{l}\text { Discharge disposition, } \\
\mathrm{n}(\%)\end{array}$ & & & .129 \\
\hline Home health care & 2212 (22.6) & $1,407,485(25)$ & \\
\hline Inpatient facility & $124(1.3)$ & $51,111(0.9)$ & \\
\hline Other transfer & $1959(20)$ & $1,407,485(19.5)$ & \\
\hline Routine/home transfer & $5455(55.8)$ & $3,056,676(54.4)$ & \\
\hline
\end{tabular}

effect of HIV status on selected outcomes after propensity-score matching is shown in Table 5. Patients with HIV were at no increased risk for inpatient mortality (odds ratio [OR], 0.98; confidence interval [CI], 0.74, 1.30). Patient with HIV infection were more likely to receive a blood transfusion (OR, 1.19; CI, 1.01, 1.40) and have any postoperative complication (OR, 1.16; CI, 1.01, 1.34), but less likely to suffer a postoperative stroke compared with those without HIV (OR, 0.43; CI, 0.25, $0.74)$. There was no difference in rates of pneumonia, renal complications, or wound infections. The median length of stay was not different between the groups (HIV+, 8 days [15th percentile, 5 days; 85 th percentile, 20 days]; HIV-, 7 days [15th percentile, 4 days; 85 th percentile, 18 days]; $P=.060$ ), nor was the mean total cost (HIV+, US $\$ 41,157 \pm 33,916$; HIV -, US $\$ 42,496 \pm 41,195 ; P=.7$ ).

Trends in cardiac surgery outcomes among patients with HIV infection are shown in Figure 3. Between 1998 and 2009 , there was a significant decline in the adjusted inpatient mortality rate from $6 \%$ to $0.7 \%(P=.021)$; the adjusted composite rate of any complication increased from $40 \%$ to $54 \%(P=.035)$. During the same time period, the incidence of endocarditis among patients with HIV infection declined from $6.9 \%$ to $4.0 \%(P=.672)$.

Among patients with HIV, metastatic cancer, coagulopathy, renal failure, and surgery type (aortic, other, or combined surgical procedure compared with CABG) resulted in an increased risk of death; the presence of 
TABLE 4. Risk-adjusted outcomes for patients with and without HIV among propensity-matched pairs

\begin{tabular}{lccc}
\hline \multicolumn{1}{c}{ Variable } & $\begin{array}{c}\text { HIV } \\
(\mathbf{n}=\mathbf{1 6 3 3})\end{array}$ & $\begin{array}{c}\text { No HIV } \\
(\mathbf{n}=\mathbf{1 6 3 3})\end{array}$ & $\boldsymbol{P}$ \\
\hline Median length of stay, & $8[5,20]$ & $7[4,18]$ & .060 \\
$\quad$ d [15th, 85th percentiles] & & & \\
Total charges, median US\$ & 77,661 & 77,290 & .006 \\
Total cost, median US\$ & 32,413 & 31,125 & .700 \\
Hospital mortality, n (\%) & & & \\
Overall & $100(6.1)$ & $102(6.2)$ & .915 \\
Pericardial surgeries & $(17.0)$ & $(16.3)$ & .905 \\
Nonpericardial surgeries & $(3.4)$ & $(4.8)$ & .068 \\
Complications, n (\%) & & & \\
Any complication & $597(36.6)$ & $541(33.1)$ & .038 \\
Stroke & $20(1.2)$ & $45(2.8)$ & .001 \\
Blood transfusion & $382(23.4)$ & $334(20.5)$ & .047 \\
Renal complication & $145(8.9)$ & $151(9.2)$ & .791 \\
Wound infection & $24(1.5)$ & $31(1.9)$ & .313 \\
Pneumonia & $156(9.6)$ & $129(7.9)$ & .086 \\
Discharge disposition, n (\%) & & & .801 \\
Home health care & $381(23.3)$ & $368(22.5)$ & \\
Inpatient facility & $20(1.2)$ & $23(1.4)$ & \\
Other transfer & $283(17.3)$ & $267(16.4)$ & \\
Routine/home transfer & $946(57.9)$ & $973(59.6)$ & \\
\hline
\end{tabular}

HIV, Human immunodeficiency virus.

anemia led to a decreased risk of death. Hospital size, insurance status, and academic affiliation did not affect mortality risk (Table 6).

\section{DISCUSSION}

Significant improvements in medical therapy have allowed patients with HIV to live much longer. However, the use of protease inhibitors has likely amplified cardiac complications both directly and indirectly. As a direct result of improved survival with HAART, patients with HIV are living longer and are more likely to develop chronic cardiovascular diseases such as $\mathrm{CAD}$, aortic pathology, and aortic stenosis. ${ }^{15}$ In addition, these drugs seem to have pleotropic effects leading to increased risk for cardiac problems.

In the 2007 Data Collection on Adverse events of AntiHIV Drugs group study of $24,437 \mathrm{HIV}+$ patients, the

TABLE 5. Effect of HIV status on propensity-matched outcomes

\begin{tabular}{lc}
\hline \multicolumn{1}{c}{ Variable } & Adjusted odds ratio $(\mathbf{9 5} \% \mathbf{C I})$ \\
\hline Total no. of patients & 3266 \\
Mortality & $0.98(0.74-1.30)$ \\
Complications & \\
$\quad$ Any complication & $1.16(1.01-1.34)$ \\
Stroke & $0.43(0.25-0.74)$ \\
Blood transfusion & $1.19(1.01-1.40)$ \\
Wound infection & $0.77(0.45-1.32)$ \\
Renal complication & $0.96(0.75-1.22)$ \\
Pneumonia & $1.24(0.97-1.58)$ \\
\hline
\end{tabular}

$C I$, Confidence interval.
TABLE 6. Risk factors for death among HIV + patients

\begin{tabular}{lc}
\hline \multicolumn{1}{c}{ Variable } & Adjusted odds ratio $(\mathbf{9 5} \% \mathbf{C I})$ \\
\hline Total no. of patients & 9771 \\
Metastatic cancer & $3.1(1.6-6.0)$ \\
Coagulopathy & $2.7(1.7-4.3)$ \\
Renal failure & $1.6(1.0-2.4)$ \\
Type of operation* & \\
$\quad$ Aortic & $6.5(2.9-14.5)$ \\
Other & $8.8(4.5-17.1)$ \\
Combined & $2.7(1.1-6.6)$ \\
\hline
\end{tabular}

$\mathrm{CI}$, Confidence interval. *Compared with coronary artery bypass graft.

relative rate of MI per year of exposure to protease inhibitors was $1.16{ }^{7}$ Thus, it seems that protease inhibitors predispose patients to develop metabolic syndrome, which then may increases the risk of accelerated cardiovascular disease at a much earlier age. However, we found that $\mathrm{HIV}+$ patients were less likely to have CABG operations. Pearce and colleagues ${ }^{16}$ have shown an increased mortality burden and lower procedural (both percutaneous coronary intervention and CABG) rates in HIV+ patients receiving care for acute MI, suggesting that there may be some element of discrimination in processes of care among $\mathrm{HIV}+$ patients with acute MI. ${ }^{16}$ We observed an unadjusted mortality rate of $7.2 \%$ in the HIV+ patients. This was driven in large part by HIV + patients undergoing pericardial drainage procedures and they likely had more advanced disease.

Other studies have examined the outcomes of cardiac surgery in HIV+ patients. ${ }^{17-19}$ Most are case studies or small single-institution reviews that, like our study, showed good outcomes with low mortality. In a retrospective review of $37 \mathrm{HIV}+$ patients Trachiotis and colleagues ${ }^{20}$ reported acceptable outcomes $(2.7 \%$ mortality rate $)$ and low complication rates (sepsis 5.4\%, deep sternal infection $2.7 \%$, bleeding $5.4 \%$, and prolonged intubation $5.4 \%$ ). Freedom from death, angina, MI, repeat revascularization, and congestive heart failure at 3 years was $81 \%$. In 2008, a case-control study of $27 \mathrm{HIV}+$ patients undergoing CABG showed no difference in 30-day rates of postoperative death, MI, stroke, mediastinitis, or reintervention compared with HIV - patients. At a mean follow up of 41 months, HIV + patients were more likely to experience death from a cardiac cause, have an MI, or undergo coronary revascularization compared with HIV - patients $(42 \%$ vs $25 \% ; P=.03) .{ }^{21}$ In this national series, we noted some differences in the regional rates of cardiac operations in HIV+ patients. Rates were higher in the northeast and south. This mirrors the general incidence of HIV disease; the northeast has $24 \%$ of new cases of HIV and the south has $45 \%$. $^{22}$

Although most studies have focused on CAD and CABG operations, we observed that $\mathrm{HIV}+$ patients were more likely to undergo valve surgery than HIV- patients. 
Increased valve operations may be a result of increased risk of infective endocarditis associated with immunosuppression and/or intravenous drug use. In a retrospective review of valve surgery in $22 \mathrm{HIV}+$ patients between 1990 and 1999 , the most common indications for surgery were sepsis in $91 \%$ and heart failure in 59\%. Staphylococcal infections were responsible for $43 \%$ of cases and Streptococcus made up 29\%; Pseudomonas and Haemophilus species accounted for $4 \%$ each. Twelve patients underwent aortic valve replacement, 7 had mitral valve replacement, and 3 had double valve replacement. There were no operative or in-hospital deaths, and 5-year survival was $55 \%{ }^{23}$ This is a great improvement over early series that reported operative mortalities of more than $20 \% .^{11,24}$ Over time, however, endocarditis has become less common as HAART therapy and antibiotic prophylaxis have improved and the burden of chronic diseases has increased by way of increased life expectancy. ${ }^{25}$ In addition, the metabolic syndrome seen in patients on protease inhibitors may also contribute to early degenerative valve disease. With regards to disease of the aorta, there is no clear understanding of the predisposing factors, although accelerated atherosclerosis and vasculitis may play a role. Vasculitis involving the aorta in HIV+ patients has been reported. Pathologic examinations reported from small studies have shown leukocytoclastic vasculitis of the vasa vasorum as a potential cause of aortic disease in $\mathrm{HIV}+$ patients. $^{26}$

A recent study examining the outcomes of HIV + patients undergoing cardiac operations also used the NIS dataset. ${ }^{27}$ They examined clinical outcomes and trends from 2000 to 2010 in patients undergoing CABG and valve surgery. Overall, their results are similar to ours, but the rates of endocarditis were reported to have decreased substantially over the study period, from about $30 \%$ to less than $10 \%$. We did not observe this trend and this may be due to the method used to query the NIS database. A study of infectious endocarditis in the United States showed that $4.8 \%$ of patients with endocarditis were HIV+ in 1998 compared with only $1.5 \%$ in $2009 .^{25}$ Furthermore, we have included propensity matching in the current study. This is important as patients with HIV tend to present at a younger age and should be compared with similar patients in order to understand the real outcomes. In addition, we were interested in morbidity outcomes and resource utilization after cardiovascular surgeries.

Overall, mortality for HIV+ patients decreased over the course of the study period. However, the rate of morbidity increased. We hypothesize that patients who may have died previously are now surviving, albeit with more complications. The component that leads to most of the complications after cardiac surgery in HIV + patients is blood transfusion. Our observation that HIV+ patients were more likely to have blood transfusion is important as we have shown that this increases the likelihood of infections such as pneumonia, and in an already immunocompromised population, this may lead to more late complications that may not be apparent in a dischargelevel database such as the NIS. ${ }^{18}$ HIV+ patients are likely receiving more blood transfusions because they have a much higher rate of anemia preoperatively. Anemia is the most common hematologic disorder in patients with HIV. Anemia in HIV+ patients has been shown to be caused by suppressed erythropoiesis and altered iron metabolism caused by inflammation, iron and folate deficiency, some types of chemotherapeutic drugs, race, sex, and the virus itself. ${ }^{28}$ It will certainly be important to understand the long-term implications of blood transfusions in this patient population in order to make the best recommendations for treatment of anemia.

In our sample, fewer patients with HIV had a postoperative stroke than similar HIV - patients. This is interesting because patients with HIV are known to have higher rates of ischemic and hemorrhagic stroke compared with age- and sex-matched HIV - patients. Lower rates of postoperative atrial fibrillation, common among HIV+ patients, may explain our observed lower rate of stroke. ${ }^{29}$ Unfortunately, we could not reliably determine the rates of postoperative atrial fibrillation from the NIS dataset.

This study provides a good understanding of the trends in cardiovascular operations for patients with HIV, but there are limitations to our work. The NIS is an administrative database, based on administrative data, and does not provide clinical information such as CD4 count or viral load. Observing that HIV+ patients are at risk for blood transfusions and any complication is important, but without accompanying clinical information, it is not possible to surmise the reasons for this or how the situation can be remedied. However, it may be prudent to address any modifiable risk factors preoperatively. Furthermore, the data are limited to events that occurred during the initial hospitalization, without information on delayed complications or readmissions. Despite these limitations, this database provided access to millions of operations and is probably most useful for this type of situation: to understand the trends of a clinical entity that is uncommon and where no single institution has a large experience. Multiple studies have used the NIS database to evaluate outcomes, epidemiology, and utilization in cardiac surgery. Because HIV + patients are typically younger than 65 years of age, datasets such as the Medicare 5\% national sample may not be applicable.

In conclusion, the treatment of HIV has prolonged the life of millions of patients, but the extension of life and the drugs used to achieve it come with the price of increased cardiovascular disease. In this study, we have shown that cardiovascular surgery can be performed safely for patients with HIV with no increase in resource utilization or 
postoperative complications aside from increased need for blood transfusion. Patients with HIV should not be denied an indicated cardiovascular surgery just because of their disease. Optimizing control of HIV preoperatively by ensuring low viral loads, reasonable immune reconstitution, and treatment of anemia may also help improve outcomes. There was a time when discussion of the chronic diseases of HIV patients was considered unnecessary, but with HAART therapy that has changed. Patients are living longer and we should expect to see more of these patients needing cardiovascular operations.

\section{References}

1. Palella FJ Jr, Delaney KM, Moorman AC, Loveless MO, Fuhrer J, Satten GA, et al. Declining morbidity and mortality among patients with advanced human immunodeficiency virus infection. HIV Outpatient Study Investigators. N Engl J Med. 1998;338:853-60.

2. Connick E, Lederman MM, Kotzin BL, Spritzler J, Kuritzkes DR, St Clair M, et al. Immune reconstitution in the first year of potent antiretroviral therapy and its relationship to virologic response. J Infect Dis. 2000;181:358-63.

3. Lederman MM, Valdez H. Immune restoration with antiretroviral therapies: implications for clinical management. JAMA. 2000;284:223-8.

4. Barbaro G, Iacobellis G. Metabolic syndrome associated with HIV and highly active antiretroviral therapy. Curr Diab Rep. 2009;9:37-42.

5. Carr A, Samaras K, Burton S, Law M, Freund J, Chisholm DJ, et al. A syndrome of peripheral lipodystrophy, hyperlipidaemia and insulin resistance in patients receiving HIV protease inhibitors. AIDS. 1998;12:F51-8.

6. Pao V, Lee GA, Grunfeld C. HIV therapy, metabolic syndrome, and cardiovascular risk. Curr Atheroscler Rep. 2008;10:61-70.

7. Friis-Moller N, Reiss P, Sabin CA, Sabin CA, Weber R, Monforte AD, et al. Class of antiretroviral drugs and the risk of myocardial infarction. $N$ Engl J Med. 2007;356:1723-35.

8. Henry K, Melroe H, Huebsch J, Hermundson J, Levine C, Swensen L, et al. Severe premature coronary artery disease with protease inhibitors. Lancet. $1998 ; 351: 1328$

9. Lang S, Mary-Krause M, Cotte L, Gilquin J, Partisani M, Simon A, et al, Increased risk of myocardial infarction in HIV-infected patients in France, relative to the general population. AIDS. 2010;24:1228-30.

10. Aris A, Pomar JL, Saura E. Cardiopulmonary bypass in HIV-positive patients. Ann Thorac Surg. 1993;55:1104-7; discussion 1107-8.

11. Mestres CA, Chuquiure JE, Claramonte X, Muñoz J, Benito N, Castro MA, et al. Long-term results after cardiac surgery in patients infected with the human immunodeficiency virus type-1 (HIV-1). Eur J Cardiothorac Surg. 2003;23: 1007-16; discussion 1016.

12. Elixhauser A, Steiner C, Palmer L. Clinical classifications software (CCS), 2014. U.S. Agency for Healthcare Research and Quality. Available at: http://www. hcup-us.ahrq.gov/toolssoftware/ccs/ccs.jsp. Accessed September 1, 2013.

13. Elixhauser A, Steiner C, Harris DR, Coffey RM. Comorbidity measures for use with administrative data. Med Care. 1998;36:8-27.

14. Austin PC, Grootendorst P, Anderson GM. A comparison of the ability of different propensity score models to balance measured variables between treated and untreated subjects: a Monte Carlo study. Stat Med. 2007;26:734-53.

15. Kirk JB, Goetz MB. Human immunodeficiency virus in an aging population, a complication of success. J Am Geriatr Soc. 2009;57:2129-38.

16. Pearce D, Ani C, Espinosa-Silva Y, Clark R, Fatima K, Rahman M, et al. Comparison of in-hospital mortality from acute myocardial infarction in HIV sero-positive versus sero-negative individuals. Am J Cardiol. 2012;110:1078-84.

17. Flum DR, Tyras DH, Wallack MK. Coronary artery bypass grafting in patients with human immunodeficiency virus. J Card Surg. 1997;12:98-101.

18. Frater RW. Cardiac surgery and the human immunodeficiency virus. Semin Thorac Cardiovasc Surg. 2000;12:145-7.

19. Imanaka K, Takamoto S, Kimura S, Morisawa Y, Ohtsuka T, Suematsu Y, et al. Coronary artery bypass grafting in a patient with human immunodeficiency virus: role of perioperative active anti-retroviral therapy. Jpn Circ J. 1999;63:423-4.

20. Trachiotis GD, Alexander EP, Benator D, Gharagozloo F. Cardiac surgery in patients infected with the human immunodeficiency virus. Ann Thorac Surg. 2003;76:1114-8; discussion 1118 .
21. Boccara F, Cohen A, Di Angelantonio E, Meuleman C, Ederhy S, Dufaitre G et al. Coronary artery bypass graft in HIV-infected patients: a multicenter case control study. Curr HIV Res. 2008;6:59-64.

22. Centers for Disease Control and Prevention. HIV Surveillance Report, 2011; vol 23. Available at: http://www.cdc.gov/hiv/topics/surveillance/resources/reports/. Accessed September 1, 2013.

23. Chong T, Alejo DE, Greene PS, Redmond JM, Sussman MS, Baumgartner WA et al. Cardiac valve replacement in human immunodeficiency virus-infected patients. Ann Thorac Surg. 2003;76:478-80; discussion 480-71.

24. Miro JM, del Rio A, Mestres CA. Infective endocarditis and cardiac surgery in intravenous drug abusers and HIV-1 infected patients. Cardiol Clin. 2003;21: 167-84, v-vi.

25. Bor DH, Woolhandler S, Nardin R, Brusch J, Himmelstein DU. Infective endocarditis in the U.S., 1998-2009: a nationwide study. PLOS ONE. 2013;8: e60033.

26. Ando T, Makuuchi H, Kitanaka Y, Koizumi H. Rupture of a pseudo aneurysm of the abdominal aorta in a patient with human immunodeficiency virus infection. Ann Thorac Cardiovasc Surg. 2011;17:198-200.

27. Polanco A, Itagaki S, Chiang Y, Chikwe J. Changing prevalence, profile, and outcomes of patients with HIV undergoing cardiac surgery in the United States. Am Heart J. 2014;167:363-8.

28. Marti-Carvajal AJ, Sola I, Pena-Marti GE, Comunian-Carrasco G Treatment for anemia in people with AIDS. Cochrane Database Syst Rev. 2011;CD004776.

29. Hsu JC, Li Y, Marcus GM, Hsue PY, Scherzer R, Grunfeld C, et al. Atrial fibrillation and atrial flutter in human immunodeficiency virus-infected persons: incidence, risk factors, and association with markers of HIV disease severity. J Am Coll Cardiol. 2013;61:2288-95.

\section{Discussion}

Dr Hossein Almassi (Milwaukee, Wis). Nice presentation. This is a timely presentation, long overdue. I still remember a time when a member of this association in Wisconsin announced to the public that he would not operate on HIV-positive patients needing cardiac operations. Of course, we have come a long way since then, and a lot of progress has been made as we heard from Dr Robich in his presentation today.

With HAART therapy, patients survive long with their chronic disease, and as cardiac surgeons, we are going to see more of this baby boomer generation with HIV requiring cardiac surgery.

The study is an analysis of a large administrative database over a 10-year period. It provides some important information; although, it suffers from the lack of patient level data, and you have admitted that in your manuscript. Information such as the stage of the HIV, the level and the length of the antiretroviral therapy, indications for surgery, urgency of the operation, and some other information are lacking.

The patients with HIV were younger than the non-HIV group with a higher rate of renal failure and liver disease but with no increase in renal complications postoperatively, but I will get to that later on.

And as you mentioned, CABG was the predominant operation in close to $40 \%$ of the patients. In propensity-matched patients, HIV-positive status had no impact on in-hospital mortality, but postoperative complications and the need for blood transfusions were significantly higher in this cohort of patients, yet there was no difference in costs between the 2 groups. That is interesting to see.

Dr Robich, I have 3 questions. I am going to ask you 1 at a time. Preoperative renal failure was a risk factor for mortality in HIV-positive patients, but the rate of postoperative renal failure 
was not different between the HIV-positive and HIV-negative patients.

Was the high rate of renal failure preoperatively distributed evenly throughout the study period, or was it more concentrated in the earlier period of this study? And if so, did you notice a difference between the outcomes of patients in the earlier part of this study versus the latter part of this study?

Dr Robich. That is a very good question. Thank you, Dr Almassi, for reading our manuscript and discussing our talk.

To answer the first question, the rates of renal failure were pretty steady throughout the study period. We did not see any large increase in renal failure over the course of the study period.

Dr Almassi. Could you tell us why patients with HIV require more blood transfusions, and you alluded to it that they did. I noted in your slides that the postoperative anemia was more prevalent in HIV-positive patients.

What would happen if you did a separate analysis excluding the anemic patients? Would the difference for the increase in transfusion rate still be significant, and if so, could you elaborate on the reasons for this increased need for blood transfusion in these patients?

Dr Robich. That is an excellent question. So the level of anemia we think is probably due in some part obviously to their HIV. We did not do that analysis of looking at it without the blood transfusion. But my suspicion is, if we did do that, that the significant increase that we saw in any complication rates would no longer be there.

And then the other part of your question was regarding whether or not ....

Dr Almassi. ... you should do a separate analysis excluding the anemic patients, preoperative anemia. Would still the difference in transfusion be significant?

Dr Robich. Right. That is a good question. We did not look at that either, and I actually do not know the answer to that. I am not sure if it would or not. I assume it would, but I do not know.

Dr Almassi. My last question is regarding the complication rate. I think you partially answered that; that it was higher in HIV-positive patients. It was interesting that it was increasing throughout the study period over the 10 years.

Did you look at the components of these morbidities to see what the predominant contributors other than anemia are? Because I think that is important information for treating physicians to figure out what to do with those factors so that the complication rate will drop down because clearly the mortality has dropped, but the complication rate is going in the opposite direction.

Dr Robich. That is exactly right.

Dr Almassi. Nice presentation. I enjoyed your presentation.

Dr Robich. Thank you very much.

So to answer your question, I think 1 of the things that ... I am sorry, I lost my train of thought. Your question again was regarding?

Dr Almassi. Components of the morbidities other than anemia.

Dr Robich. Oh, right. I am sorry.

Dr Almassi. Have you looked at the components of morbidity to see what they are, the significant contributors of this increasing rate of morbidities so that then surgeons and physicians can deal with it and to come up with strategies to take care of those?
Dr Robich. Right. I think 1 of the reasons that we saw increased complication rates and lower mortality is that there probably were patients in the past who were dying, and because of better care, we were able to rescue them from death. And, unfortunately, they probably suffered more complications as they may have died before, but now they have a complication. That is 1 reason.

The second thing that is interesting is there are several modifiable risk factors that I did not present today but that we have noticed and that would be important. One of the things that we found would be the coagulopathy. I think if we address that and if we maximize the therapy for their HIV and address any fluid and electrolyte imbalances, those were all risk factors as well for complications.

So I think there are modifiable risk factors we can address to further improve outcomes.

Dr Charles M. Geller (New York, NY). Thank you for this thought-provoking presentation. Having had the opportunity to operate on many HIV-positive patients each year for the past 2 decades, I believe that all immunodeficient patients are not alike.

Were you able to determine either a viral load level or a CD4/T-cell count cutoff level at which outcomes in this patient population were affected?

Dr Robich. That is an excellent question and I think a critical thing to understand. Unfortunately, this database does not have that type of clinical data in it, so we do not know what their CD4 status was. But I think that is an important point.

Dr Mark S. Slaughter (Louisville, Ky). Along those same lines, there is a difference between being HIV-positive and having AIDS, so your risk of other, which was essentially open pericardial windows and cancer, are those just surrogate markers for patients who have systemic disease and significant immunosuppression?

Dr Robich. That is an excellent point. That is our belief that these patients are probably a lot more advanced in their disease, may not have had adequate medical treatment beforehand, and I would agree with that.

Dr Slaughter. Lastly, you made the comment that there were fewer strokes, and you believed this was due to the immunomodulation. Predominantly and particularly in coronary surgery, it is an embolic event related to the atherosclerotic load.

So what immunomodulating effect decreases the atherosclerotic load in these patients?

Dr Robich. Well, that is a good question as well, and I do not know if it is completely due to the immunomodulation or decreasing inflammation in general.

And also, as I pointed out, they had less peripheral arterial disease, and it may be just a factor of them being younger and not having developed a heavy atherosclerotic burden at this point.

Dr Giuseppe D'Ancona (Palermo, Italy). You mention valve operations. I was wondering, do you have any specific data about HIV-positive patients who are drug addicts and the recurrence of endocarditis or infection because I would presume that then the results are somewhat different.

Dr Robich. Well, that is true. And about $6 \%$ of the patients in our study over the entire period had endocarditis. However, we did not look at them separately, endocarditis versus nonendocarditis valve operations, but certainly that would likely have an impact.

Dr Edward G. Soltesz (Cleveland, Ohio). So when we did this analysis, we actually did the analysis with smaller subgroups as 
well. We did subgroup analysis of only doing CABG, isolated $\mathrm{CABG}$, isolated valve aortic surgery only, thoracic aortic surgery. We get a smaller number obviously, but the outcomes are exactly the same.

We included the larger group practice, including those other cardiovascular surgeries, mainly open pericardial drainages, because that is sort of our practice in our entire department. And we figured because we are going to see them, these types of patients, we want to sort of know what their outcomes are going to be in general.

The second issue is to comment on the stroke. So it is very interesting. In HIV patients as a whole, the incidence of ischemic stroke and hemorrhagic stroke is increasing, but the incidence of atrial fibrillation is lower. So you could potentially make the connection that these patients, although we cannot necessarily determine this from this database, that they have less postoperative atrial fibrillation, and as you said, less embolic events.

Dr Frank W. Sellke (Providence, RI). I think another way to look at that is people with HIV may have less of an inflammatory response, and with the same atherosclerotic burden or emboli, you do not have the inflammatory influence to propagate the stroke.

And the same thing with atrial fibrillation. You have less inflammation, so you may have less atrial fibrillation because of that reason.

Dr Robich. I would agree with that, Dr Sellke. 